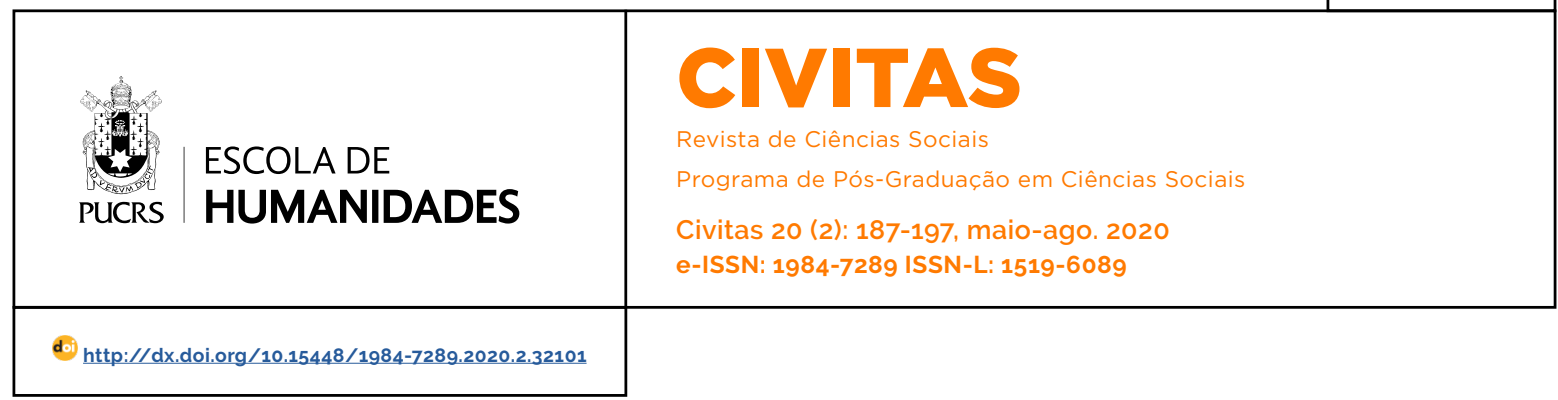

DOSSIÊ: MEIO-AMBIENTE EM DISPUTA

\title{
Quando o desenvolvimento sustentável esconde o óbvio: violação de direitos e os limites da justiça ambiental no caso da proibição de circulação de carroças em Porto Alegre
}

\author{
When sustainable development hides the obvious: violation of rights and the limits of \\ environmental justice in the case of the prohibition of the circulation of horse-drawn \\ carts in Porto Alegre
}

Cuando el desarrollo sostenible oculta lo obvio: violación de los derechos y los límites de la justicia ambiental en el caso de la prohibición de circulación de carrozas en Porto Alegre

\section{Roberta Camineiro Baggio ${ }^{1}$ orcid.org/0000-0003-4907-6105 roberta.baggio@ufrgs.br}

Recebido em: 30 set. 2018 Aprovado em: 11 mai. 2020. Publicado em: 4 ago. 2020 . (c) (1)
Artigo está licenciado sob forma de uma licença
Creative Commons Atribuição 4.0 Internacional.
Resumo: O presente artigo busca problematizar, em um cenário marcado pelas narrativas de desenvolvimento sustentável, a insuficiência do conceito de injustiça ambiental como uma questão distributiva a partir da análise do caso da proibição de circulação de carroças na cidade de Porto Alegre. Propõe-se a análise teórica das situações de injustiça ambiental a partir da teoria do reconhecimento que, ao buscar compreender as causas de desrespeito social, pode contribuir para o desvelamento do cinismo existente em propostas de modernização ecológica que utilizam a proteção da natureza para manter ou produzir modos de exclusão social. Palavras-chave: Justiça Ambiental. Desenvolvimento sustentável. Teoria do reconhecimento.

Abstract: The present article tries to problematize, in a marked by the narratives of sustainable development scenario, the insufficiency of the concept of environmental injustice as a distributive issue by analyzing the case of the prohibition of movement of carts in the city of Porto Alegre. It proposes the theoretical analysis of situations of environmental injustice based on the theory of recognition that, in seeking to understand the causes of social disrespect, can contribute to the unveiling of cynicism in the proposals for ecological modernization that use the protection of nature to maintain or produce modes of social exclusion.

Keywords: Environmental justice. Sustainable development. Recognition theory.

Resumen: Este artículo busca problematizar, en un escenario marcado por las narrativas del desarrollo sostenible, la insuficiencia del concepto de injusticia ambiental como un tema distributivo a partir del análisis del caso de la prohibición de la circulación de coches de caballos en la ciudad de Porto Alegre. Se propone un análisis teórico de situaciones de injusticia ambiental basado en la teoria del reconocimiento que, al tratar de entender las causas de la falta de respeto social, puede contribuir a la revelación del cinismo existente en las propuestas de modernización ecológica que utilizan la protección de la naturaleza para mantener o producir modos de exclusión social.

Palabras clave: Justicia ambiental. Desenvolvimiento sustentable. Teoria del reconocimiento.

\section{Introdução}

As reivindicações por justiça ambiental são relativamente recentes na história das sociedades contemporâneas e a construção de sua conceituação ocorre em um cenário complexo, envolvendo tanto a temática 
da justiça quanto a da proteção da natureza. Uma parte considerável dessa complexidade está posta no fato de que as discussões sobre a necessidade de proteção ambiental estão situadas entre dois polos que guardam um alto potencial gerador de violações a direitos: por um lado, a defesa inconteste da natureza como fonte moral, que ignora a necessidade de afirmação da autonomia e da identidade humanas e, por outro, a manutenção dos padrões atuais de produção e consumo, reunidos sob a tutela do desenvolvimento sustentável. No contexto marcado por esses dois polos encontra-se o caso tratado nesse artigo: o da proibição da circulação das carroças na cidade de Porto Alegre.

A "onda" da reciclagem que surgiu no contexto da sociedade de consumo foi legitimada como um mecanismo de desenvolvimento sustentável que impulsionou uma indústria extremamente lucrativa, beneficiária tanto da exploração do trabalho das populações que tiram seu sustento do lixo, como do acréscimo de valor agregado aos produtos rotulados como "sustentáveis".

As lutas por justiça ambiental denunciam em situações como essa que os catadores de lixo suportam um peso maior dos processos de degradação ambiental em relação a outras parcelas da população economicamente incluídas.

O objetivo do artigo é demonstrar a insuficiência dessa concepção distributiva diante de estratégias que antagonizam seres humanos e natureza, como no caso analisado, em que a lógica do desenvolvimento sustentável originou uma narrativa de discriminação dos carroceiros em prol da proteção dos cavalos.

O artigo defende uma ampliação da concepção de justiça ambiental, a partir dos pressupostos da teoria do reconhecimento, especificamente na versão desenvolvida por Axel Honneth. Essa escolha metodológica deriva do fato principal de que sua abordagem teórica percebe os processos de exclusão social distributivos como uma experiência de negação do reconhecimento do valor social das pessoas, indicando a qualidade moral das relações em sociedade e a limitação de propostas distributivas que tendem a repetir os mesmos padrões de exclusão.

$\mathrm{O}$ artigo está dividido em três partes. Na primeira é apresentada uma noção histórica da consolidação da ideia de justiça ambiental e sua relação com o tema do desenvolvimento sustentável. Na segunda, o caso concreto é apresentado e, na terceira, é demonstrada a potencialidade da teoria do reconhecimento de Axel Honneth para a análise do caso e a reconstrução de uma concepção de justiça ambiental como reconhecimento.

\section{Justiça ambiental e a desfaçatez da} lógica do desenvolvimento sustentável

Um dos grandes desafios enfrentados pelo movimento por justiça ambiental, ao longo da década de 1970, foi o embate com os movimentos ambientalistas pela redefinição das concepções tradicionais de proteção e preservação do meio ambiente. Isso porque tais movimentos tiveram uma ação direcionada para a proteção do meio ambiente in natura. Nesse início, a questão ambiental ainda não se constituía como pauta principal das reivindicações sociais, ficando restrita a poucos grupos que denunciavam o modo de vida predador desenvolvido ao longo da modernidade.

Defendiam, portanto, uma visão oposta aos movimentos de luta por justiça ambiental, uma vez que generalizavam a ação humana, colocando-a como foco principal a ser combatido para a preservação da natureza. Já o movimento por justiça ambiental, denunciava a injustiça sofrida por seres humanos pela concentração dos efeitos nocivos dos processos de degradação em suas comunidades, caracterizadas, em geral, pela exclusão econômica e social.

Em 1990, os movimentos de luta por justiça ambiental enviaram cartas às dez maiores organizações de proteção ambiental expondo as criticas em relação à sua atuação restrita, esclarecendo os prejuizos para as comunidades atingidas por processos de injustiça ambiental e convidando a um diálogo mais aberto (Sandler e Pezzullo 2007, 19).

Muitas dessas críticas foram aceitas e surtiram efeitos positivos no sentido de ampliar os debates sobre a importância do meio ambiente nos centros urbanos, por exemplo. Dentre as principais organizações que incorporaram essa nova pers- 
pectiva destacam-se o Greenpeace, Sierra Club e Earth Island Institute. Contudo, mesmo argumentando que o ser humano é parte da natureza e que, portanto, lutar pela melhoria das condições de seu ambiente seria também lutar por essa natureza, havia um temor de que a incorporação da perspectiva das lutas por justiça ambiental enfraquecesse o combate ao antropocentrismo moderno. Portanto, muitos movimentos ambientalistas mantiveram sua linha inicial de atuação sob o entendimento de que qualquer guinada ao antropocentrismo poderia descaracterizar as bandeiras eminentemente voltadas à proteção ambiental (Sandler e Pezzullo 2007, 312).

Para além das divergências entre ambientalistas tradicionais e militantes por justiça ambiental, há um perigo que afronta tanto a perspectiva de proteção e preservação do meio ambiente quanto às reivindicações por justiça ambiental: a cooptação do discurso de proteção do meio ambiente pelos setores vinculados ao mercado capitalista, que passaram a perceber um potencial altamente lucrativo proporcionado pela sensibilização da sociedade em relação às questões ambientais.

Inicialmente, os grupos que denunciavam os efeitos nocivos da ação humana sobre a natureza não eram levados a sério e, inclusive, eram tidos como inimigos do progresso, ficando até mesmo conhecidos por expressões como "ecochatos, ecomaníacos e ecorromânticos" (Ramos 1995, 118). O fato é que, por um lado, o aumento significativo de desastres ambientais no mundo todo e o crescente apoio da opinião pública contribuíram para reverter esse jogo, abrindo espaço para uma percepção inovadora sob o ponto de vista capitalista. A apropriação direta dos recursos naturais para incrementar os processos produtivos, como representação do progresso humano, acabou sendo substituída pelas práticas politicamente corretas de produção a partir da utilização de tecnologias que possibilitam que o meio ambiente seja supostamente "poupado".

É importante notar que a aplicação de ações permeadas pela lógica do politicamente correto para o meio ambiente, rumo a um novo direcionamento do processo de produção, não implicou em uma mudança do modo de vida moderno como se reivindicava em um primeiro momento, a exemplo da não diminuição das taxas de consumo. Ao contrário, essa lógica inovadora tem contribuído para reforçar o consumo, só que agora, considerado como "sustentável". De acordo com pesquisa realizada pelo Instituto Akatu, sobre o panorama do consumo consciente no Brasil, 38\% dos entrevistados haviam incorporado hábitos sustentáveis em suas práticas de consumo frente aos 32\% em 2012. ${ }^{2}$

Ou seja, é como se, de fato, a sociedade contemporânea - ou ao menos uma parcela dela tivesse alcançado a tão esperada harmonização entre as questões econômicas e de proteção da natureza. No entanto, é preciso considerar a ilusão gerada por essa perspectiva, bem como as possiveis distorções que ficam escondidas por detrás da crença da harmonização entre economia e meio ambiente.

A questão do lixo é paradigmática nesse sentido e demonstra toda a perversidade que pode estar contida na nova "onda" de desenvolvimento sustentável.

Em uma pesquisa sobre a reciclagem no municipio de São Paulo, na década de 1990, Sabetai Calderoni (2003, 289), já havia demonstrado em números as contrariedades da sustentabilidade:

Os resultados revelam que a indústria aufere a maior parte dos ganhos alcançando $\mathrm{R} \$$ 215 milhões, correspondentes a 66\% do total obtido através do processo de reciclagem do lixo, tendo como perspectiva ganhos de até R\$ 852 milhões, caso a reciclagem venha a atingir integralmente a quantidade possivel. Os ganhos obtidos pelos sucateiros com a reciclagem são da ordem de $\mathrm{R} \$ 32$ milhões, $10 \%$ do total; sua perspectiva é de ganhos de até $\mathrm{R} \$ 75$ milhões. Aos carrinheiros e catadores é atribuida a parcela de R\$ 43 milhões, a qual poderia chegar a R\$100 milhões.

A concentração dos lucros nas mãos das empresas desvela sua grandiosidade diante do grande número de catadores de lixo, mão de obra primordial para reciclar, que se submetem a um trabalho de tipo informal, sem acesso a qualquer 
direito trabalhista, beneficiando a "indústria da reciclagem" (Burgos 2008).

As controvérsias aumentam ainda mais se considerarmos a supervalorização econômica que tem recaído sobre esses produtos fruto da reciclagem, a partir do discurso da proteção ambiental, o que a torna um verdadeiro "[...] álibi, de forma que essa nova mercadoria aparece ao consumidor com um valor unicamente simbólico (de proteção da natureza), camuflando-se seu real valor econômico" (Layrargues 2002, 205).

A pior parte desse processo é que o Brasil, mesmo sendo um dos países que mais faz reciclagem de alumínio, não reduziu sua exploração de bauxita, principal recurso natural para a produção de alumínio (Layrargues 2002, 194). Essa situação gera uma falsa sensação de compatibilidade entre consumo e preservação da natureza representada em muito de seu significado pela expressão desenvolvimento sustentável (Montibeller Filho 2004, 283).

A onda de desenvolvimento sustentável faz parte de um cenário de modernização ecológica em que prevalece a crença de que as tecnologias limpas serão capazes de superar a crise ecológica, sem que se tenha que alterar significativamente o padrão de comportamento instaurado na modernidade. A questão principal é que esse padrão de comportamento implica em uma série de circunstâncias de aprofundamento de concentração de renda e de desigualdades sociais (Acselrad 2004, 23).

Há, portanto, uma incompatibilidade insuperável entre as lutas por justiça ambiental e a perspectiva da modernização ecológica, no sentido de que essa modernização não está ao alcance de todos, reforçando o processo de exclusão e exploração social por meio, muitas vezes, de um discurso de proteção da natureza.

\section{A proibição da circulação de carroças em Porto Alegre: quem ou o que de fato importa ao sistema capitalista?}

A formação de uma indústria da reciclagem, que nas últimas décadas aperfeiçoou seus métodos de ampliação de lucros, revela as grandes vantagens de cooptação da perspectiva de proteção ambiental pelo sistema capitalista. Legitimada pela construção de uma narrativa de viabilidade do sistema econômico, por meio do slogan do desenvolvimento sustentável, a assunção de uma perspectiva de proteção ambiental pela indústria da reciclagem oferece "paz" aos consumidores que desejam manter seus níveis de consumo - desde que separem o lixo orgânico do lixo seco e consumam produtos sustentáveis -, ao mesmo tempo em que coloca à disposição dos poderes públicos municipais a diminuição do montante de residuos sólidos a serem geridos por meio dos aterros sanitários.

Sob o argumento de diminuir a situação de indignidade dos catadores de lixo e qualificá-los para fazerem melhor o serviço de separação e triagem dos resíduos sólidos, no início dos anos 2000 diversos municípios brasileiros começaram a implementar leis proibindo a circulação de veículos de tração animal e de tração humana (VTA's e VTH's) para direcionar por meio da qualificação profissional parte desse público vulnerável para atividades econômicas alternativas ou da própria reciclagem (Stroh 2016). Esse processo desembocou, inclusive, na criação da Lei 12.305/2010 que instituiu a Política Nacional de Resíduos Sólidos.

Foi nesse contexto, acrescido de uma alta mobilização de ativistas de proteção animal em defesa dos cavalos e da melhoria do trânsito que, em 16 de junho de 2008 foi aprovado na Câmara de Vereadores da cidade de Porto Alegre, por meio da Lei 10.531, o Programa de Redução Gradativa do Número de Veículos de Tração Animal e Humana, que implicaria na retirada de circulação das carroças e carrinhos das ruas da cidade no prazo de oito anos.

O projeto inicial de modernização do processo de reciclagem foi proposto no ano de 2005 , pelo vereador Sebastião Melo, que apresentou, na exposição de motivos, dois argumentos. Um social, que considerava a inadmissibilidade de que "[...] pessoas, em pleno século 21, tenham que se sujeitar a condições de vida da época medieval" e o outro de proteção animal, "[...] pois o mau-trato e a falta de condições mínimas a que estão submetidos os cavalos são do conhecimento de todos, com larga notícia pela mídia". A versão final do projeto foi aceita e defendida por diversos setores da sociedade civil, principalmente por 
ONG's de proteção dos animais, que entregaram aos vereadores, antes da sessão de votação, um abaixo-assinado com cerca de cinco mil assinaturas a favor do projeto. Os catadores protestaram durante toda a sessão alegando que o desemprego iria aumentar com a medida de proibição da circulação das carroças. ${ }^{3}$ A Lei aprovada revelou uma série de inconsistências que acabaram gerando conflitos entre os atores sociais envolvidos, ao invés de propor soluções viáveis aos problemas tanto dos carroceiros quanto dos cavalos.

O incentivo da criação de cooperativas e de retirada dos carroceiros das ruas para a sua realocação nos galpões de triagem do lixo indica que o maior sucesso da Lei até agora foi avançar na garantia de uma reserva de mercado para empresas de recolhimento de resíduos sólidos que se consolidaram isoladamente na coleta seletiva e que continuarão se beneficiando da mão de obra barata e informal dos catadores que estão a um baixíssimo custo fazendo o trabalho de triagem e separação do lixo seco nos galpões.

Ainda que a aplicação da Lei estivesse condicionada "[...] à existência de formas alternativas de geração de renda e sobrevivência econômica dos condutores de VTA's", nunca houve qualquer garantia de que, de fato, tais ações pudessem ser implementadas, já que o poder legislativo não tem ingerência sobre o poder executivo. Assim, a previsibilidade de efetivação da Lei ficou reduzida a duas alternativas: ou nenhuma proposição de solução sairia do papel, pelo alto grau de dependência da Lei com a implementação de políticas públicas, ou sairia de forma equivocada, priorizando a proibição da circulação dos VTAs, sem o devido cuidado na garantia da reinserção econômica de seus condutores no mercado trabalho, beneficiando a indústria da reciclagem. Passados mais de dez anos do surgimento da
Lei Municipal 10.531/08 a segunda alternativa continua mais forte, como será analisado.

O calendário de proibição do tráfego de carroças foi estabelecido e alterado várias vezes pela dificuldade de alcance dos resultados planejados inicialmente pelo programa "Todos Somos Porto Alegre", sobretudo pela não finalização do cadastramento dos carroceiros, instrumento que serviria de base para traçar o perfil de demandas laborais a serem contempladas pelos cursos de capacitação prometidos como alternativa econômica a essa população.

Na última decisão da Câmara de Vereadores, em maio de 2017, foi prorrogado o início da proibição total da circulação das carroças e dos carrinhos até 2020, ainda que em algumas zonas a proibição já estivesse valendo. A dificuldade de algumas zonas já estarem com restrição total da circulação é o risco de catadores ainda não cadastrados ficarem sem alternativa de atividade econômica, já que não poderão ter acesso aos cursos.

Em outras situações, a participação nos cursos é dificultada pelas próprias circunstâncias de exclusão social a que estão submetidos. Para Venâncio Francisco de Castro, presidente da Associação dos Moradores, Carroceiros e Papeleiros da Ilha Grande dos Marinheiros:

\begin{abstract}
A lei é contraditória e não é amparada pela legislação federal. Promessas foram feitas, como o galpão de reciclagem na Voluntários da Pátria, que não saiu. Recebemos semana passada a informação de que os cursos profissionalizantes estão abertos, mas não podemos sair daqui com tanta água 4 . Só se vierem nos buscar de barco. Os outros cursos foram pela metade. Como o de massa caseira, por exemplo, que durou uma semana e só teve um dia de prática. Assim não adianta. ${ }^{5}$
\end{abstract}

No mesmo sentido das críticas levantadas por Venâncio encontra-se a representação entregue

\footnotetext{
3 Câmara de vereadores de Porto Alegre. 2008. Carroças: Vereadores aprovam retirada das ruas em oito anos. Acessado em: 17 jun. 2018, http://www.camarapoa.rs.gov.br/.

Projeto de Lei 976/05. Acessado em: 17 jun. 2018, http://200.169.19.94:4000/sisprotweb/processo_detalhe/69324?pagina_atual=1\#.

4 Nos dias anteriores à veiculação dessa matéria havia chovido na cidade de Porto Alegre por vários dias seguidos. A referência de Venâncio de que os carroceiros não teriam como sair das ilhas diz respeito à antiga questão de inundação das ilhas que, associada às condições inapropriadas de moradia dessas populações, faz com que, em situações desse tipo, se tornem literalmente ilhadas até que o nivel da água do rio Guaiba volte ao normal.

5 Berrnardi, Ronaldo. 2013. Lei que retira carroças das ruas da Capital começa a valer no domingo. Zero Hora, 30 de ago.2013. Acessado em 29 set.2013. https://gauchazh.clicrbs.com.br/geral/noticia/2013/08/lei-que-retira-carrocas-das-ruas-da-capital-comeca-a-valer-no-domingo-4251948.html
} 
ao Ministério Público do Trabalho (MPT) em 27 de setembro de 2013 pelo Serviço de Assessoria Juridica Universitária da Ufrgs (Saju/Ufrgs). De acordo com o documento, além da mesma constatação de que nenhuma nova Unidade de Triagem havia sido construída até então, a tentativa da prefeitura em oferecer aos catadores cursos de formação profissional seria um equivoco em vários sentidos.

Primeiramente porque o cadastramento não estava completo e não se tinha, portanto, um quadro fidedigno sobre a real demanda de pessoas para os cursos, o que também dificultou as possibilidades do poder público direcionar os cursos de acordo com os diversos perfis de catadores, na medida em que muitos poderiam não apresentar requisitos básicos para cursá-los, como a própria alfabetização. ${ }^{6}$

Em janeiro de 2017, a cooperativa Mãos Limpas, entidade da sociedade civil gerenciadora do projeto "Inclusão Produtiva dos ex-condutores de VTA e VTH", pertencente ao programa governamental "Porto Alegre Para Todos", apresentou em seu relatório final dados concretos sobre a implementação do cadastro dos catadores. O projeto registrou 2.059 pessoas vinculadas à atividade de recolhimento de lixo reciclável. Contudo, esse dado demonstrou-se incompleto ao longo da execução do projeto, uma vez que as equipes se depararam com um número superior a esse, alcançando "2.632 pessoas abordadas" até dezembro de 2016 (Voigt 2017, 5).

Mesmo sem especificar o significado concreto da expressão "pessoas abordadas", esse fato demonstra que os catadores não foram alcançados em sua integralidade e que os projetos desenvolvidos pela prefeitura não conseguiram, nem ao menos, mapear com alguma precisão o montante de pessoas atingidas pela implementação da Lei, já que o número de "2.632 pessoas abordadas" pelo projeto guarda inconsistência com os dados do IBGE, que contabilizaram 3.755 catadores na cidade de Porto Alegre. ${ }^{5}$

O relatório também traz dados sobre a quantidade de pessoas consideradas, até final de 2016 , "inseridas em novas formas de sustentação", o que não significa que as pessoas tenham obtido necessariamente um emprego formal com carteira assinada, mas que iniciaram nova atividade ou benefício com renda, indicando um total de 828 pessoas (Voigt 2017, 5). Se, considerado o número total de pessoas "abordadas" pelo projeto, esse número representa um parco 31\% de acesso a algum tipo de atividade econômica, que não representa necessariamente a inserção no mercado de trabalho. Se o número total considerado de catadores for o do IBGE, esse índice cai para $22 \%$.

O relatório cita, ainda, indenizações fornecidas pelos bens VTA ou VTH, que atingiram a 375 pessoas, totalizando 14\% de beneficiados, considerando o número do próprio relatório do total de pessoas "abordadas". Diante do número do IBGE, esse índice cai para 10\%.

Diante do cenário exposto fica difícil sustentar o alcance da integração social por um processo em que a proibição das carroças foi colocada como prioritária em relação à inclusão econômico-social das pessoas que tiram seu sustento diretamente dessas atividades. A desconfiança e a descrença dos catadores, representadas nas palavras de Venâncio, em relação a um poder público que parece estabelecer alternativas de sustentação econômicas meramente aparentes enquanto as carroças e carrinhos são retirados de circulação, torna-se compreensivel.

As incongruências presentes no processo de implementação da Lei 10.531/08, no entanto, não se restringem somente a esses fatos. A proteção dos cavalos, que foi a principal estratégia de convencimento e de legitimação social que levou à aprovação da Lei, com amplo apoio de ONGs de proteção dos animais, tampouco foi garantida até esse momento. ${ }^{7} \mathrm{O}$ art. $5^{\circ}{ }^{\circ}$ do Decreto $18.409 / 13$.

\footnotetext{
6 Serviço de Assessoria Jurídica Universitária da Ufrgs (Saju/Ufrgs). 2013. Representação apresentada ao Ministério Público do Trabalho em 27 set. 2013, sob o protocolo n. ${ }^{\circ} 010054$.

7 Nesse sentido, vale a pena destacar o argumento de Maria Carman, no artigo El caballito de Boedo y el cartonero sin nombre: um abordaje critico de los derechos humanos, no sentido de que o grande problema das perspectivas de defesa da dignidade dos animais não é a existência de tal defesa em si, mas o fato de que, em geral, vem acompanhada de uma reafirmação dos padrões de exclusão social: “ ¿No se corre el riesgo de que ciertos predicamentos que en apariencia impugnan el antropocentrismo y son contrarios a toda práctica colonial, difuminen más y más el rostro de los vulnerables hasta quitarles toda existencia social? Contamos con sobrados ejemplos de una empatía hipertrofiada hacia los animales que suelen correr en paralelo a una empatía atrofiada hacia los humanos más sufrientes". (Carman 2015, 206)
} 
determina que os animais recebidos no processo de entrega voluntária das carroças serão recolhidos ao abrigo da cidade e posteriormente serão destinados à adoção através da Empresa Pública de Transporte Coletivo (EPTC). Além do fato de que o artigo se restringe aos cavalos espontaneamente entregues pelos carroceiros, não se trata de uma garantia de auxilio ou amparo a esses animais, que desaparecerão das vistas públicas, seja porque serão entregues em um primeiro momento, ou então, porque a posteriori serão proibidos de circular. Contudo, não deixarão de existir e de necessitar de melhores condições de tratamento.

Não há dúvidas de que há uma séria questão socioambiental nas circunstâncias que envolvem os carroceiros e os cavalos da cidade de Porto Alegre, o que se questiona é como foi supostamente resolvida. A condição socioeconômica na qual se encontram faz com que os carroceiros vejam a Lei como um processo discriminatório, pois pertencem a uma parcela da população que vive em uma situação de invisibilidade social. Muitos deles residem nas ocupações irregulares das ilhas do Delta do Jacuí, sem acesso a direitos sociais básicos, o que de antemão já lhes retira a possibilidade de uma condição juridica de igualdade de tratamento.

A grande ironia desse cenário é que uma série de restrições a direitos estão sendo implementadas sob a fundamentação da melhoria social das condições de vida dos carroceiros e, também, de proteção da natureza e dos cavalos, sem que necessariamente haja qualquer garantia de que seres humanos e animais sairão desse contexto em condições mais benéficas.

\section{Teoria do reconhecimento aplicada}

\section{à justiça ambiental: tentativas de desvelamento da desfaçatez da lógica do desenvolvimento sustentável.}

Os movimentos de luta por justiça ambiental têm cumprido o importante papel de denunciar que a incorporação da preocupação de proteção da natureza pela lógica capitalista é fictícia e acaba deslocando os processos de degradação para localidades em que estão instaladas populações economicamente menos favorecidas ou vulneráveis, fazendo com que haja uma distribuição desigual do acesso aos bens ambientais e uma sujeição maior dessas populações aos riscos inerentes aos processos de produção.

A perspectiva da justiça distributiva, contudo, vincula-se a um debate de materialização e quantificação das relações sociais que não alcança, de forma adequada, o processo de complexificação social em que se somam às discriminações e opressões tradicionais o elemento de proteção da natureza.

O que se pretende demonstrar é que a teoria do reconhecimento, na perspectiva de Axel Honneth, fornece os aportes necessários para que se possa compreender de uma forma mais complexa o fenômeno da injustiça ambiental. As denúncias de uma distribuição injusta dos bens e riscos ambientais passam a ser percebidas, sob o ponto de vista dessa teoria, como processos de recusa das formas de reconhecimento. Ou seja, há outras circunstâncias que também precisam ser integradas ao conceito de injustiça ambiental e que não se referem, necessariamente, a questões distributivas.

Na visão proposta por Honneth há um equivoco na avaliação de que os conflitos por reconhecimento indicam um novo perfil de demandas sociais, fruto da virada cultural consolidada nas últimas décadas nas sociedades contemporâneas. ${ }^{8}$ Para o autor, a ausência de uma distribuição justa é indicativa de uma experiência de desrespeito que caracteriza um processo de negação dos padrões de reconhecimento. O que Honneth busca com essa avaliação é a unificação da bipolarização formada entre injustiças econômicas e culturais, pela análise das implicações morais que permeiam a teoria do reconhecimento (Honneth 2006a,124).

A existência de uma distribuição injusta dos bens e das riquezas produzidos em sociedade atesta e demonstra que o não reconhecimento

\footnotetext{
8 Esse é o principal argumento na defesa da perspectiva dualista da teoria do reconhecimento de Nancy Fraser. Para sustentar que existem dois paradigmas da justiça - o da redistribuição e o do reconhecimento - , que se constituem como duas faces da mesma moeda (a justiça), a autora articula os dois conceitos sob o ponto de vista da moral, priorizando, assim, seus supostos conteúdos universais em detrimento das concepções de vida boa. Não há, portanto, uma integração entre tais conceitos, mas uma releitura da ideia de reconhecimento, retirando-a do âmbito da ética para colocá-la ao lado do paradigma distributivo.
} 
do valor social de pessoas e de grupos é o que leva a uma situação de discriminação no momento da definição dos critérios distributivos. Conceber, portanto, os conflitos sociais como conflitos distributivos é uma limitação decorrente da própria tradição da teoria social critica, que vinculou a ideia de motivação dos conflitos sociais ao conceito de interesse (Honneth 2003 , 260), explorando uma perspectiva estritamente econômica e materialista (Honneth 2006a, 108). Vincular a injustiça social a um processo desencadeado por uma distribuição não adequada é insuficiente para compreender a "qualidade moral das relações sociais", já que essas "[...] não podem ser mensuradas exclusivamente em termos de uma distribuição justa ou equitativa dos bens materiais" (Honneth 2007, 81).

Demonstrado o equivoco de se construir uma dicotomia entre conflitos sociais por distribuição e por reconhecimento e, decorrendo dessa conclusão a necessidade de conceber esse último de um modo muito mais amplo, indo além da dimensão cultural, é preciso responder, então, ao questionamento sobre como a ideia de processo de reconhecimento é desenvolvida por Honneth. Essa seria a etapa de pensamento em que o autor demonstra como é possivel formar uma concepção plural de justiça, construida a partir de principios normativos que indicam os padrões de reconhecimento existentes nas sociedades modernas.

A inspiração de Honneth, para a abordagem das formas de reconhecimento, são os escritos de juventude de Hegel, em que o filósofo identifica e desenvolve três etapas do reconhecimento, viabilizadas por relações intersubjetivas estabelecidas entre os sujeitos, que possibilitam tanto a formação de seus horizontes éticos, como o progresso moral da sociedade (Honneth 2003, 117).

O que importa aqui é o desenvolvimento da ideia de que a passagem por cada uma das etapas de reconhecimento se dá em forma de uma luta travada pelo sujeito, como modo de alcançar uma situação de autonomia, que the permita atingir uma melhor compreensão de si mesmo. É nesse sentido que a formação da identidade dos sujeitos está diretamente vinculada a "lutas por reconhecimento".
O primeiro padrão de reconhecimento é aquele obtido por meio das relações afetivas. No processo de reconhecimento social, os sujeitos buscam a construção de sua autoconfiança pelas relações intimas, estabelecidas desde a infância, que permitem o exercício de um certo grau de autonomia pela segurança alcançada no processo reciproco de dedicação afetiva. A relevância desse padrão diz respeito não só à constituição da segurança individual dos sujeitos, para o exercício de sua liberdade, mas também se constitui como ".... a base indispensável para a participação autônoma na vida pública" porque permite o estabelecimento de relações intersubjetivas de confiança (Honneth 2006b, 178).

O segundo padrão é o do reconhecimento jurídico e constitui-se na possibilidade de exercício do autorrespeito não apenas no âmbito das relações intimas, mas em um espaço público, como condição de reciprocidade necessária ao desenvolvimento das relações intersubjetivas entre parceiros integrados e igualmente incluidos em um sistema universalizado de garantia de direitos (Honneth 2003, 195).

A terceira forma de reconhecimento se dá pela comunidade de valores ou solidariedade e vincula-se à ideia de estima social. Para além do reconhecimento pela igualdade universalizada, a partir da condição de humanidade, os sujeitos carregam uma expectativa de que as suas singularidades também devem ser reconhecidas como valiosas: "[...] a reputação social dos sujeitos se mede pelas realizações individuais que eles apresentam socialmente no quadro de suas formas particulares de autorrealização" (Honneth 2003, 208).

Na modernidade, essa terceira dimensão de reconhecimento se consolidou culturalmente sob a influência do desenvolvimento do sistema econômico capitalista, que permitiu um novo padrão ético de valorização do esforço individual transformado em força de trabalho (Honneth 2006a, 111). A estima social, que antes estava vinculada ao nascimento, à propriedade, à tradição familiar e a todas as outras formas de hierarquia social constituidas como fontes garantidoras da ideia de honra, passa agora a depender do "[...] êxito individual na estrutura da divisão de trabalho organizada no plano industrial" (Honneth 2006a, 111). 
A instituição de um princípio do êxito, nas sociedades capitalistas, pautado pela valorização do desempenho individual na divisão social de trabalho, cumpre a função de legitimação normativa que permite justificar publicamente as desigualdades econômicas e sociais, a partir da construção de uma compreensão de que a riqueza e o mérito individual, no desenvolvimento das atividades laborais, são grandezas vinculadas. Para corroborar ainda mais tal legitimação, a própria ordem juridica, ao proporcionar uma condição de igualdade inicial a todos, ratifica a ideia de que a produção de desigualdades sociais ou de uma distribuição de bens e riquezas não equitativa reflete a postura de cada um no grau de dedicação ao trabalho.

Para cada uma das possibilidades de compreensões positivas, que os sujeitos podem alcançar por meio dos modos de reconhecimento - a autoconfiança, o autorrespeito e a autoestima, derivadas respectivamente das relações de afeto, juridicas e da comunidade de valores -, correspondem formas negativas de interação, ou ainda, de reconhecimento recusado, derivadas de experiências de ofensa e de desrespeito geradoras de situações de injustiças que abalam não só o processo de socialização moral dos sujeitos, mas sua efetiva integração como membros autônomos e capazes de atuar positivamente em seu entorno social (Honneth 2006a, 136).

A primeira forma de recusa do reconhecimento é a violência física, caracterizada pelos maus-tratos corporais, provocadoras de sentimentos de humilhação e vergonha social. Esse é o modo mais elementar de rebaixamento pessoal, e o abalo moral dessa situação não se resume à dor física exposta ao mundo, mas à impossibilidade de perceber-se compreendido na sua relação com o outro e com o mundo (Honneth 2003, 215).

A segunda forma de desrespeito atinge o autorrespeito do sujeito, pois nesse caso, há uma recusa do reconhecimento de sua condição de igualdade juridica pela ausência no acesso aos direitos universalmente garantidos. A situação de privação de direitos implica na impossibilidade de o sujeito perceber-se como um ser imputável moralmente, ou seja, "[...] a denegação de pretensões juridicas socialmente vigentes significa ser lesado na expectativa intersubjetiva de ser reconhecido como sujeito capaz de formar juízo de valor moral [...]" (Honneth 2003, 216).

A terceira forma de reconhecimento recusado é aquela que degrada valorativamente os modos de vida dos sujeitos ou de grupos, afetando a concepção positiva da autoestima dos indivíduos, de forma que deixem de se sentir estimados por suas habilidades e capacidades. No âmbito de uma coletividade, esse tipo de desrespeito ou ofensa produz um sentimento que Honneth denomina como vexação: "[...] a experiência do rebaixamento e da humilhação social, os seres humanos são ameaçados em sua identidade da mesma maneira que o são em sua vida física com o sofrimento de doenças" (Honneth 2003, 219).

A consequência mais nefasta das formas de reconhecimento recusado é que elas ocasionam uma quebra da própria relação de legitimação do Estado de Direito em sua consolidação como um Estado democrático.

No caso analisado, as formas de desrespeito são produzidas institucionalmente e buscam, como base de legitimidade, a adoção de uma narrativa de proteção da natureza e dos próprios carroceiros, o que dificulta consideravelmente a percepção desse tipo de injustiça, pois aparentemente existem fundamentos "nobres" envolvidos nessas circunstâncias, que estão vinculados à proteção das pessoas e do meio ambiente. A proteção dos cavalos somada aos beneficios de uma reciclagem mais "ordenada", promovida pela "onda" do desenvolvimento sustentável, que tiraria carroceiros das ruas para colocá-los nos galpões de triagem do lixo inseridos no processo "produtivo", seriam iniciativas indiscutivelmente benéficas.

Contudo, quando se reflete que as restrições propostas representam processos tanto de exclusão da condição de igualdade no acesso a direitos universais quanto de aprofundamento do desrespeito pelo modo de vida das populações envolvidas, a fundamentação de legitimidade inicial não pode ser sustentada, pois o progresso moral da sociedade é construído por meio da 
ampliação das formas de reconhecimento determinantes para o aumento do que Axel Honneth chama de nivel moral de integração social.

Todas as incongruências que têm permeado a implementação da Lei 10.531/08 se potencializam diante da análise de que o principal processo de recusa de reconhecimento, nessa situação, é o da depreciação da importância da atividade por eles desenvolvida. Essas pessoas garantiam sua sobrevivência do recolhimento dos restos descartados pela sociedade, o que os coloca em um contexto degradante pela própria forma como se valora socialmente esse tipo de serviço. A implementação da Lei piorou esse cenário, na medida em que os poucos dados estatísticos oficiais, vinculados ao programa Todos Somos Porto Alegre, demonstram que $70 \%$ ou mais catadores de lixo ficaram sem qualquer alternativa econômica de sobrevivência.

Dificil imaginar possibilidades de construção de autoestima por parte desses sujeitos que, ao desenvolver seu papel diante do mundo, se encontram em circunstâncias tão desvantajosas em termos econômicos e sociais.

Não há qualquer perspectiva distributiva na situação dos carroceiros que permita a superação do sentimento de vexação ao qual o grupo está submetido, seja pelo desenvolvimento da atividade de recolhimento de lixo para alimentar a ilusão da sociedade de consumo, seja pela reivindicação de proteção dos cavalos, que contribuiu para a construção de uma imagem de malfeitores diante de toda a sociedade. Nessa última situação é possivel afirmar, inclusive, a ocorrência de um processo de negação identitária da própria condição de humanidade, uma vez que ao lado do sentimento de proteção dos animais concorre o desprezo social e a proibição de manutenção da atividade de subsistência desses sujeitos.

Por isso, a injustiça ambiental deve ser percebida não apenas em situações que envolvem uma distribuição equivocada tanto dos bens como dos riscos ambientais, mas como processos de desrespeito, materializados pela negação das formas de reconhecimento, que representam ofensas morais produzidas a partir da própria questão ambiental.

\section{Considerações Finais}

A Lei 10.531/2008 do município de Porto Alegre, assumindo uma perspectiva de desenvolvimento sustentável, estabeleceu a proibição de circulação de carroças sob o manto argumentativo de melhoria das condições de vida das populações que retiram do lixo suas condições de subsistência e da proteção dos cavalos utilizados para a coleta do lixo. O anúncio de programas sociais de inclusão econômica com cursos que capacitariam os catadores a trabalharem nos galpões de triagem de lixo ou ensinariam outras atividades remuneratórias, assumiu uma clara vertente de tentativa de integração distributiva, tanto sob um ponto de vista econômico quanto sob um ponto de vista ambiental, já que essas pessoas deixariam de exercer um trabalho degradante saindo das ruas da cidade.

Em mais de uma década de vigência, alguns resultados da implementação da Lei suscitam considerações no sentido contrário à sua fundamentação inicial. O fato de que a grande beneficiária da nova Lei foi a indústria da reciclagem, que acabou com a concorrência na coleta seletiva, direcionando apenas alguns catadores aos galpões de reciclagem que passaram a fornecer a matéria prima para a indústria sem o custo de direitos trabalhistas, é um exemplo.

Carroceiros continuam sendo explorados sem inserção no mercado formal de trabalho e sem a garantia de que receberão mais pelo trabalho desempenhado na triagem do lixo. Como tais galpões não tiveram um aumento significativo, como prometido pelo poder público, muitos catadores não puderam ser absorvidos por esse mercado informal e estão condenados a novas situações de exclusão social.

Uma concepção de injustiça ambiental, restrita à tentativa de denunciar a má distributividade econômica e de riscos ambientais a que são submetidas algumas populações, teria dificuldades de desvelar a permanência da situação de injustiça de carroceiros.

A teoria do reconhecimento não se limita à consideração de que a ausência de distributividade é o problema em si que permeia a maior parte das 
questões sociais de economias capitalistas, mas pressupõe na ausência de distributividade uma experiência de desrespeito que não será superada apenas com medidas distributivas. O caso dos carroceiros em Porto Alegre demonstra isso. Apesar da adoção oficial de medidas distributivas como acesso a cursos e indenização das carroças, os processos de negação do reconhecimento são mantidos no novo cenário.

Propõe-se, assim, que a justiça ambiental seja concebida a partir dos aportes teóricos da teoria do reconhecimento, que tem um potencial de desvelar a incompatibilidade entre inclusão social e desenvolvimento sustentável, quando esse assume uma narrativa de modernização ecológica e de promoção da proteção da natureza para manter os níveis de exclusão social.

\section{Referências}

Acselrad, Henri. 2004. Justiça ambiental - ação coletiva e estratégias argumentativas. In Justiça ambiental e cidadania, organizado por Henri Acselrad, Selene Herculano e José Augusto Pádua, 23-39. Rio de Janeiro: Relume Dumará.

Calderoni, Sabetai. 2003. Os bilhões perdidos no lixo. São Paulo: Humanitas.

Carman, María. 2015. El caballito de Boedo y el cartonero sin nombre: un abordaje crítico de los derechos animales. Revista Theomai 32: 189-209.

Honneth, Axel. 2006a. Redistribución como reconocimiento. Respuesta a Nancy Fraser. In Redistribución o reconocimiento? organizado por Nancy Fraser e Axel Honneth, 89-148. Madrid: Paidéia-Morata.

Honneth, Axel. 2006b. La cuestión del reconocimiento: réplica a la réplica. In Redistribución o reconocimiento? organizado por Nancy Fraser e Axel Honneth, 176-196. Madrid: Paidéia-Morata.

Honneth, Axel. 2007. Reconhecimento ou redistribuição? A mudança de perspectiva na ordem moral da sociedade. In Teoria critica no século XXI, organizado por Jessé Souza e Patrícia Mattos, 79-93. São Paulo: Annablume.

Honneth, Axel. 2003. Luta por reconhecimento: a gramática moral dos conflitos sociais. São Paulo: Editora 34.

Layrargues, Philippe Pomier. 2002. O cinismo da reciclagem: o significado ideológico da reciclagem da lata de alumínio e suas implicações para a educação ambiental. In Educação ambiental: repensando o espaço da cidadania, organizado por Carlos Frederico Bernardo Loureiro, Philippe Pomier Layrargues e Ronaldo Souza de Castro, 179-220. São Paulo: Cortez.
Montibeller Filho, Gilberto. 2004. O mito do desenvolvimento sustentável: meio ambiente e custos sociais no moderno sistema produtor de mercadorias. Florianópolis: Ufsc.

Ramos, Luis Fernando Angerami. 1995. Meio ambiente e meios de comunicação. São Paulo: Annablume.

Sandler, Ronald e Phaedra C. Pezzullo. 2007 Introduction: revisiting the environmental justice challenge to environmentalism. In Environmental justice and environmentalism: the social justice challenge to the environmental movement, organizado por Ronald Sandler e Phaedra C. Pezzullo, 1-24. Cambridge: MIT.

\section{Roberta Camineiro Baggio}

Doutora em Direito pela Universidade Federal de Santa Catarina (Ufsc), Florianópolis, SC, Brasil. Professora associada da Faculdade de Direito da Universidade Federal do Rio Grande do Sul (Ufrgs), Porto Alegre, RS, Brasil. 